\title{
Experiment of Prepared Zinc Powder from Hot-Dip Galvanizing Zinc Dross
}

\author{
Xunhua Yuan* and Qifu Zhang \\ National Engineering Laboratory of Advanced Coating Technology for Metals, Central Iron \& Steel Research Institute, Beijing \\ 100081, China \\ ${ }^{*}$ Corresponding author
}

\begin{abstract}
With the facts that the hot-dip galvanizing industry continues to develop, the output of hot-dip galvanizing dross increased unceasingly and the zinc resources reduces constantly, the problem of the hot-dip galvanizing dross regenerative recovery has became the focus of the industrial circle, Therefore, this paper put forward on the concept that using hot-dip galvanizing dross to prepare zinc powder directly from the reclaim and recycle of the zinc resource; And prepared zinc powder at the ordinary pressure according to the physicochemical characteristics of zinc that the vapor pressure of hot-dip galvanizing will change exponential near the melting point; and observed the exterior pattern of zinc powder, analyzed the distribution of grain size and determined the content of zinc.
\end{abstract}

Keywords - hot-dip galvanizing; zinc dross; zinc powder

\section{INTRODUCTION}

Hot-dip galvanizing is one abroad method in the ferrous material anticorrosion. Which is a technical method that putting the metal (matrix) material into low melting point molten metal, such as liquid zinc or zinc alloy after pretreatment, the steel matrix is corroded and solved by liquid zinc, Carry out galvanizing and form film, so get the preventive cladding ${ }^{[1]}$. Hot-dip galvanizing had got fast development in recent years as a conventional aseptic technique. Along with the development of the society and the quality of life increase ceaselessly, the demand for galvanizing products increase increasingly ${ }^{[2]}$. Because of the fast development of galvanizing industry, the zinc dross that produced quantity could also increase rapidly, so that reduced the utilization rate of zinc; and lots of zinc dross can also affect the quality of the galvanizing coating, in the course of hot-dip galvanizing, the zinc that form zinc dross occupy approximately $12 \% \sim 15 \%$ to the total consumption of zinc. In the course of hot-dip galvanizing, could format zinc dross because of the metallurgical reaction of iron and zinc, cause the mobility of zinc liquid to change badly, reduce the utilization rate of zinc, make the thickness of coating increase, and affect the quality of galvanizing coating. According to statistics, in 2006, the output of zinc exceeded three millions tons in our country, if the content of zinc that used to hot-dip galvanizing was $40 \%$, the dosage of hot-dip galvanizing could reach to $1,200,000$ tons annual, and the output of zinc dross occupy approximately $12.5 \%$ to the consumption of zinc, so the annual output of zinc dross is approximate 150,000 tons, and cause the cost of the galvanization to increase enormously ${ }^{[3]}$ [4]. Especially in the situation of the price of zinc increases always; zinc resource decreases continuously, and the situation of the demand increases continuously, the growth mechanism, the formation cause and the research of retexture method of hot-dip galvanizing zinc dross were got recognition increasingly. Therefore, the research on recycling of hot-dip galvanizing zinc dross are becoming more and more important [5] [6].

Whereas, the output of the zinc dross that produced every year was very large, if the zinc dross was not reclaimed and utilized reasonable, on the one hand, that will cause the great waste of resource; on the other hand, that could provoke the problem of the environmental pollution and the consume of other primary material, human power, material resources. These were not commensurate with the background of our country that was still a developing country, along with our country extracted to build a economize society and the request for environmental protection increased continuously, which need to pay more attention to the recycling of zinc dross. Traditionally, the prepared method of zinc powder was to make the zinc dross to zinc ingot metal first, then using the zinc ingot metal to prepare zinc powder mainly. Therefore, this article had put forward on the concept that using hot-dip galvanizing dross to prepare zinc powder directly, and constituted the reasonable experiment craft route which according to the physicochemical characteristics of metal zinc that near the melting point the vapor pressure of hot-dip galvanizing will change exponential, that disposed the hot-dip galvanizing dross to prepare zinc powder according to the characteristic of zinc and zinc iron alloy; Then tested and analyzed the prepared zinc powder with scanning electron microscopy, X-ray diffraction, fluorescence spectra and other modern means, contrast with the mechanical plating special-purpose zinc powder, which included the analysis of chemical constitution and the analysis of particle size etc.

\section{EXPERIMENTATION MATERIALS AND METHOD}

\section{A. Experimental Material and Equipment}

1) Experimental Material. The hot dip galvanizing zinc dross of this experimentation is the zinc scruff, which was produced by some hot-dip galvanizing product line, the content of the aluminum is higher in the zinc dross, analyzed the zinc dross through the X-ray fluorescence spectra and the content of components was shown in the Table1. 
TABLE I. THE COMPOSITION (WT.\%) OF HOT DIP GALVANIZING DROSS

\begin{tabular}{ccccccc}
\hline Zn & Al & Fe & S & P & Ni & Pb \\
\hline 64.988 & 18.995 & 15.881 & 0.0297 & 0.0069 & 0.0121 & 0.087 \\
\hline
\end{tabular}

2) Experimental Equipment. The zinc powder was prepared by the hot-dip galvanizing dross stove, which was designed independently. The particle size of zinc powder was measured by the particle size indicator. The morphology of zinc powder was observed with XL30ESEM-TMP scanning electronic microscope. And the chemical composition of zinc powder was analyzed by ZSX100e $\mathrm{X}$-ray fluorescence spectra analysis apparatus.

\section{B. Experimental method}

The experimental was mainly used the principle of the zinc vapor pressure and the temperature that submit the exponential law, when the metal zinc was liquid, the increment speed of vapor pressure was very slow initially, and when the temperature arrived at a certain extent (for zinc, the temperature was $750{ }^{\circ} \mathrm{C}$ ), the zinc vapor pressure will increase rapidly, but other metal impurities were not been evaporated or the evaporating capacity was very little[1], so the zinc element volatilized first and became the zincous evaporation, then made that to shock chilling in the condensator, so get the zinc powder, and achieved the aim of purifying the hot-dip galvanizing dross. The prepared zinc powder were checked and analyzed though the mentioned above experimental installation.

\section{RESULTS AND DISCUSSION}

The zinc powder were made by the adequate experimental temperature, cooling temperature and cooling velocity, the granularity of the zinc powder were analyzed by the particle size indicator, and discovered that the zinc powder that less-than $2 \mu \mathrm{m}$ was about $45 \%$, the zinc powder that greater than $2 \mu \mathrm{m}$ and less than $4 \mu \mathrm{m}$ was about $35 \%$, and the zinc powder that greater than $4 \mu \mathrm{m}$ was about $20 \%$.

\section{A. X-ray Fluorescence Spectra Analysis Apparatus}

The chemical composition of zinc powder was analyzed by X-ray fluorescence spectra analysis apparatus, and the result show that the content of the mental zinc in the prepared zinc powder was obvious higher than that in the hot-dip galvanizing dross; the composition of zinc powder was shown in the Table 2. As can be seen from Table 2 that the content of the mental zinc in the prepared zinc powder had increased obviously, the pureness increased to $99.793 \%$ from $64.988 \%$. And the content of other impurity elements such as $\mathrm{Al}, \mathrm{Fe}, \mathrm{S}, \mathrm{P}, \mathrm{Ni}, \mathrm{Pb}$ was reduced obviously.

TABLE II. THE COMPOSITION (WT.\%) OF ZINC POWDER

\begin{tabular}{cccccc}
\hline Zn & Al & Fe & S & P & Pb \\
\hline 99.793 & 0.0724 & 0.0561 & 0.0233 & 0.0025 & 0.0527 \\
\hline
\end{tabular}

\section{B. The Morphology of Zinc Powder}

The pattern of zinc powder were observed by the SEM, and discovered that the zinc powder were all spherical, which was prepared by the method of evaporation-condensation, and there were lots of little particle that cemented each other, the surface topography of zinc powder was shown in the Fig.1. This was because the zinc liquid drop would make itself spheroidization as the effect of the interfacial force, before it was over-cooling and solidifying, assured the superficial area was least, so that made the ultimate production become spherical. The zinc powder that had solidified or half solidified could become cool substrate for the no-freezing or half-freezing drop, made the zinc powder that was no-freezing to take place splat cooling and solidified, and cemented each other, when the zinc powder that had solidified or half solidified bumped the zinc powder that was not solidified or half solidified on the course of sedimentation. So the big zinc powder had complete sphericity, but the little particles appeared different degree of random geometry. This kind of cementation may be also that the little liquid drop nucleated and splat cooling on the particles that had solidified. Along with the particle size of the zinc powder reducing, the ratio of the intact crystal face occupy the total surface reduced, and the ratio of the material particles (atom, molecule) of undersaturation bond force occupy the total material particles increased. The refined particle had high surface activity, such as high chemical reactivity, high adsorptive capacity, and high coherency. The huge superficial area and high surface activity of the superfine zinc powder had very important meaning, especially in the course of mechanical plating.

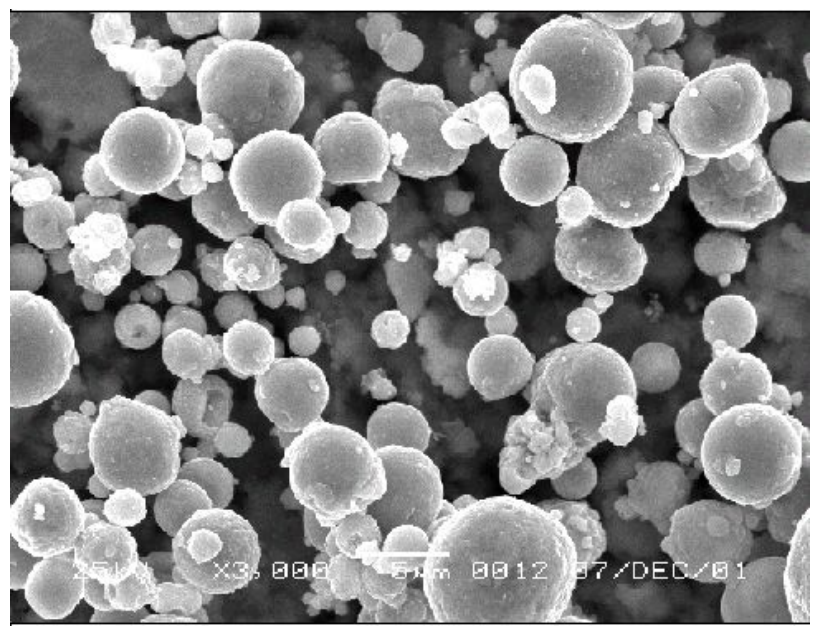

FIGURE I. SEM MICROGRAPH OF ZINC POWDER.

The zinc powder are crystalline, and the manufacturing method was very importance for the crystal structure of zinc powder. Solid is different from liquid, the surface of liquid was smooth and homogeneous to a certainty, if the liquid was static, but the solid was different from that, and its surface have miscellaneous deficiencies. Although the zinc powder were spherical, the surface was not particularity and smoothness as we imagined. We can also discover that the surface of the zinc powder assumes typical cellular structure, from the SEM of the single zinc powder such as Fig.1, the surface was roughness, and has obvious short comings such as fault, sidestep, and inclusion and so on. This is because the zinc powder were formative after atomization condensation and crystal, so there must exist lots of lattice defect at the surface of zinc powder. Obviously, there exist bit bare, dislocation and interstitial atom in the zinc particles, or made the crystal lattice take place distortion because of existing gas, oxide, impurity. The defects on the zinc powder were the state that deviate the regular crystallization, for the following formal defects: 
1) The point defect: bit bare, replacement atom, clearance. This kind of defects in the zinc powder could produce at the course of heating and crystal, and that also could produce by the effect of the external stress. Otherwise, this could produce because of the movement of the line defect, which would take a very important action for the reason of mechanochemistry.

2) The line defect: dislocation. The line defect was formed because of the mechanical deformation of crystal or the crystal lattice, became the line defect along with the direction of line because of the heat stress. The line defect had two basic styles, which is the edge dislocation and the spiral dislocation.

3) The face defect: stack defect, grain boundary, and fault. The face defect was caused by the stress of zinc powder's surfaced atom became asymmetric, as it was solidified and crystal, the dispose of surfaced atom became irregular, formed uncompleted stack layer, and the surface appeared excessive penetration and bulge.

\section{The Analysis of X-ray Diffraction}

The zinc powder were inspected by X-ray diffraction (the target metal is $\mathrm{Cu}$, the tube voltage of is $40 \mathrm{Kv}$, the tube current is $80 \mathrm{~mA}$, the monochromator is plumbago), the XRD atlas was shown in the Fig.2, and discovered that the diffraction peaks that appeared in the atlas were the most characteristic peaks of the zinc powder, there were only six characteristic peaks that were corresponded with the zinc oxide in the atlas, and the peak value of the diffraction peaks was very small, which were corresponded with the six characteristic peaks of the zinc oxide, which shown the prepared zinc powder had only little zinc oxide powder; there were no other impurity peaks, and the model of the peaks were very sharp, so the crystal of the zinc powder was very full, the purity quotient of the powder was very high.

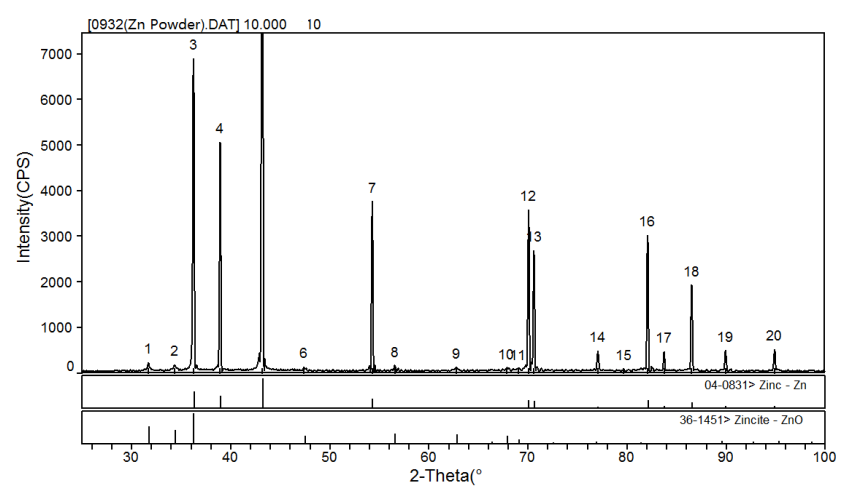

FIGURE II. X-RAY DIFFRACTION PATTERN OF THE ZINC POWDER.

\section{CONCLUSIONS}

Through theoretical research analysis, using the physicochemical characteristics of zinc which near the melting point the vapor tension of the metal zinc will submit the exponential, which could reach to the purpose of purifying the zinc dregs, and form the metal zinc powder directly. The appearance of the zinc powder is spherical completely, and the particle size distribution of the zinc powder was narrower and uniform, the grain size was small, and which meet the demand of the mechanical plating special-purpose to the zinc powder; the content of the metal zinc in the zinc powder was higher to reach $99.793 \%$, and the content of the impurity composition could reduce 2-3 order of magnitude than the content of the impurity in the hot-dip galvanizing dross.

\section{ACKNOWLEDGMENT}

In this paper, the research was sponsored by the National Nature Science Foundation of China (Project No. 51071052) and National High Technical Research and Development Program of China (Project No. 2012BAJ13B03).

\section{REFERENCES}

[1] A.R. Marder. The metallurgy of zinc-coated steel[J]. Progress in Materials science, 45(2000): 191-195.

[2] Sun Lian-chao, TIAN Rongzhang. Zinc and Zinc Alloy Physical Metallurgy[M]. Changsha: Central South University of Technology Press, 1994.12.

[3] Huang Zhucheng, CAI Jiangsong, YANG Yong-bing. Comprehensive Recovery of Valuable Elements from Zinc-leaching Residue [J]. Multipurpose Utilization of Mineral Resources, 2002.6, 3: 46-49.

[4] Ren Yunsen, LI Yongqian, FENG Changbao. Study on Two-step Zinc Regeneration Technology from Zinc Slag During Hot-dip Galvanizing Process [J]. Bao-Steel Technology, 2003, 1: 60-62.

[5] Ma Chun. Production of Pure Zinc by Electrorefining of Hot Galvanizing Slag[J]. Shanghai: Shanghai Nonferrous Metals:2002, 2: 79-85.

[6] Ma Chun. Production of Pure Zinc by Electrorefining of Hot Galvanizing Slag[D]. Shanghai: Shanghai University, 2003.

[7] Yuan Xunhua, Research of the technologic theory and equipment principle of using hot-dip galvanizing dross to prepare zinc powder by the method of evaporation-condensation[D]. Kunming: Kunming University of Science and Technology, 2007. 